\title{
Protection of Cyclooxygenase Activity during Heme-Induced Destabilization
}

\author{
MARTIN E. HEMLER AND WILLIAM E. M. LANDS \\ Department of Biological Chemistry, The University of Michigan, Ann Arbor, Michigan 48109
}

Received January 8, 1980

\begin{abstract}
Sheep vesicular gland cyclonxygenase is destroyed spontaneously when incubated with only substoichiometric amounts of heme. Peroxides may participate in this destruction, since glutathione peroxidase, catalase, and phenol, a cosubstrate for prostaglandin hydroperoxidase, all protect the cyclooxygenase activity. Stoichiometric or greater levels of heme also tend to protect the enzyme from inactivation. Therefore, to achieve optimal recoveries of enzyme activity during purification and storage, the addition of prostaglandin hydroperoxidase cosubstrate, such as phenol, in combination with high levels of heme is recommended. The current understanding of destabilization and protection of cyclooxygenase now allows an interpretation of the previously unexplained phenomenon of slow phenol activation of cyclooxygenase acetone powder preparations. Phenol appears to protect enzyme activity during the slow equilibration of apoenzyme with endogenous heme to form the active holoenzyme. In the absence of phenol, the progressive rise in activity is not seen as the enzyme is vulnerable to heme-induced destruction.
\end{abstract}

The initial step in the conversion of arachidonic acid to prostaglandins and related derivatives is catalyzed by the microsomal enzyme, cyclooxygenase. The ovine enzyme (from sheep vesicular glands) requires heme which is tightly bound as a prosthetic group (1-3). The bovine enzyme also requires heme (4) from which it is readily dissociated (5). In addition to free hematin, a variety of hemeproteins, including hemoglobin and myoglobin, can provide the heme necessary for activity $(2,4-6)$.

Attempts to purify and study the cyclooxygenase from ovine vesicular glands have been hampered by enzyme instability $(1,7-$ 9 ). Recently, while attempting to prepare holoenzyme, Ogino et al. (5) noted that heme caused a rapid destabilization of bovine vesicular gland cyclooxygenase $(50 \%$ inactivation in a few minutes). However, several agents such as epinephrine, hydroquinone, tryptophan, and phenol provided protection. The mechanism of the destabilizing process was not resolved since removal of $\mathrm{O}_{2}$ or addition of scavengers for peroxide, superoxide, singlet oxygen, and hydroxy radical did not appear to protect the cyclooxygenase (5). Almost without exception, the compounds which stabilized cyclo- oxygenase activity during storage with heme, acted as cosubstrates (5) for the prostaglandin hydroperoxidase activity which is associated with cyclooxygenase (10). However, the mechanistic relationships between protection and hydroperoxidase activity have not yet been addressed.

Phenol was reported to allow a slow, time dependent activation of acetone powder preparations of sheep vesicular gland cyclooxygenase $(11,12)$. Although the mechanism of activation was not known, it was noted that the phenol activated form of the enzyme (Ea), ${ }^{1}$ but not the unactivated form (Eb), could be inhibited by glutathione peroxidase (12).

The present report examines both the destabilization and the protection of ovine cyclooxygenase, and the results establish optimal conditions for preserving enzyme activity. Furthermore, a new interpretation of the phenomenon of slow "phenol activation" $(11,12)$ of cyclooxygenase acetone powder preparations has been proposed.

\footnotetext{
1 Abbreviations used: Ea, activated form of enzyme; Eb, unactivated form of enzyme; DDC, sodium diethyldithiocarbamate; SDS, sodium dodecyl sulfate; GSP, glutathione peroxidase; GSH, glutathione.
} 
TABLE I

The Destablizing Effect of Low Heme CONCENTRATIONS UPON TOTAL CyClOOXYGENASE ACTIVITY

\begin{tabular}{llc}
\hline Experiment & \multicolumn{1}{c}{ Conditions } & $\begin{array}{c}\text { Percentage } \\
\text { inactivation }\end{array}$ \\
\hline A. Isoelectric & 8\% Holoenzyme & 12 \\
focusing & $75 \%$ Holoenzyme & 75 \\
B. Biogel P-30 & - Heme & 26 \\
& + Heme & 100 \\
C. Biogel A- & - Heme & 52 \\
$0.5 \mathrm{M}$ & + Heme & 98 \\
& - Heme, + globin & 46 \\
& + Heme, + globin & 52 \\
\hline
\end{tabular}

"In experiment A, preparations of cyclooxygenase (8\% holoenzyme, 150,000 units; $75 \%$ holoenzyme, 400,000 units) were purified by isoelectric focusing at $4^{\circ} \mathrm{C}$ for $22 \mathrm{~h}$ as described (1). In experiment $\mathrm{B}$, purified apoenzyme $(0.9 \mathrm{ml}, 19,500$ units $/ \mathrm{mg}, 0.28 \mathrm{mg})$ in $20 \%$ glycerol in $0.02 \mathrm{M}$ Tris-chloride $(\mathrm{pH} 8.0$ ) was chromatographed $(1 \times 41 \mathrm{~cm})$ at $4^{\circ} \mathrm{C}$ with and without the addition of $1.21 \mu \mathrm{M}$ hematin. In experiment $\mathrm{C}$, apoenzyme ( $0.8 \mathrm{ml}, 20,000$ units $/ \mathrm{mg}, 0.4 \mathrm{mg})$ in $20 \%$ glycerol in $0.02 \mathrm{M}$ Tris-chloride $(\mathrm{pH} 8.0)$ was chromatographed $(1 \times 49 \mathrm{~cm})$ at $4^{\circ}$ with or without the addition of $1.1 \mu \mathrm{M}$ hematin or $2 \mathrm{mg}$ of globin.

\section{MATERIALS AND METHODS}

Materials. Sheep vesicular glands were generously donated by the Upjohn Company, Kalamazoo, Michigan. Sodium diethyldithiocarbamate (DDC), glutathione, and myoglobin were from Sigma Chemical Company, St. Louis, Missouri. Hemin chloride, from Calbiochem, San Diego, California, was initially dissolved in $0.1 \mathrm{~N} \mathrm{NaOH}$, then diluted into $0.1 \mathrm{M}$ Tris-
$\mathrm{HCl}$ and adjusted to $\mathrm{pH}$ 8.0. Heme concentrations were determined by the reduced pyridine hemochromagen method of Falk (13). Globin was prepared from myoglobin by the method of Teale (14), and glutathione peroxidase was prepared from erythrocytes by L. De Filippi (University of Michigan) and assayed as described by Cook and Lands (15). Acetone powder (16) and purified cyclooxygenase were prepared from sheep vesicular glands as described earlier $(1,17)$. Bovine liver catalase (10,800 Sigma units/ml) was obtained from Sigma and assayed spectrophotometrically ( $\Delta A_{240}$ per min; 18 ) or polarographically (oxygen released from $10 \mathrm{mM} \mathrm{H}_{2} \mathrm{O}_{2}$ ).

Quantitation of cyclooxygenase. Enzyme activity (1 nmol oxygen/min at optimum velocity equals 1 unit) was determined polarigraphically (17) in $3 \mathrm{ml}$ chambers containing $0.1 \mathrm{M}$ Tris $-\mathrm{HCl}, 50-100 \mu \mathrm{M}$ arachidonic acid and $0.67 \mathrm{~mm}$ phenol. In experiments involving apoenzyme, 016-1.0 $\mu \mathrm{M}$ hematin was added to the assay mixture. The amount of apoenzyme present was determined by subtracting the holoenzyme activity (enzyme units observed in the absence of added heme) from the total activity (units observed in the presence of $0.6-1.0 \mu \mathrm{M}$ hematin).

Protein concentrations were determined by the Lowry method or by quantitative scanning of SDS gels (1), and calculation of subunit concentration for purified cyclooxygenase preparations was based on a molecular weight of 70,000 per subunit $(2,9)$. Purified enzyme was routinely used unless otherwise indicated.

\section{RESULTS}

\section{Heme-Induced Spontaneous Inactivation of Cyclooxygenase during Storage}

Heme caused low recoveries of activity during the purification of cyclooxygenase (Table I). Substantial inactivation occurred when endogenous heme (holoenzyme) was present $(A)$ or when hematin was added (B

TABLE II

Stability of Apoenzyme and Holoenzyme ${ }^{\prime}$

\begin{tabular}{lccc}
\hline Enzyme preparation & $\begin{array}{c}\text { Holoenzyme } \\
\text { (assay - heme) }\end{array}$ & $\begin{array}{c}\text { Total enzyme } \\
\text { (assay + heme) }\end{array}$ & $\begin{array}{c}\text { Apoenzyme } \\
\text { (difference) }\end{array}$ \\
\hline I. DEAE-cellulose & 490,000 & 670,000 & 180,000 \\
II. Biogel A-1.5M & 310,000 & 550,000 & 240,000 \\
III. Isoelectric focusing & 100,000 & 350,000 & 250,000 \\
IV. Storage, 1 month & 3,000 & 220,000 & 217,000 \\
$\quad$ at $-70^{\circ} \mathrm{C}$ & & 2 & \\
\hline
\end{tabular}

"Cyclooxygenase from DEAE-cellulose was treated with globin $(\sim 4 \mathrm{~g})$ and further purified as described (17). Activity (total units) with 20:4 was determined at each stage plus or minus $0.67 \mu \mathrm{M}$ hematin as indicated under Materials and Methods. 
and $\mathrm{C}$ ), compared with preparations with little or no heme content. This apparent heme-induced destruction was prevented when excess globin was added to complex with heme (C). Cyclooxygenase isolated after chromatography with globin was entirely apoenzyme indicating that all of the hematin initially added was either destroyed or bound to the globin. Globin alone did not alter the stability of the enzyme.

Further evidence for the destabilizing effect of heme is shown in Table II. To achieve higher recovery of active cyclooxygenase during purification, globin was added to partially purified enzyme following DEAEcellulose chromatography (I) in an attempt to remove the heme. More apoenzyme was recovered in subsequent purification steps (II and III), and this apoenzyme remained relatively stable. In contrast, the holoenzyme was selectively lost during successive purification steps.

The effect of varied levels of heme on the stability of purified cyclooxygenase at $21-23^{\circ} \mathrm{C}$ is shown in Fig: 1. Whereas increased destabilization was observed with an increase in hematin concentration from

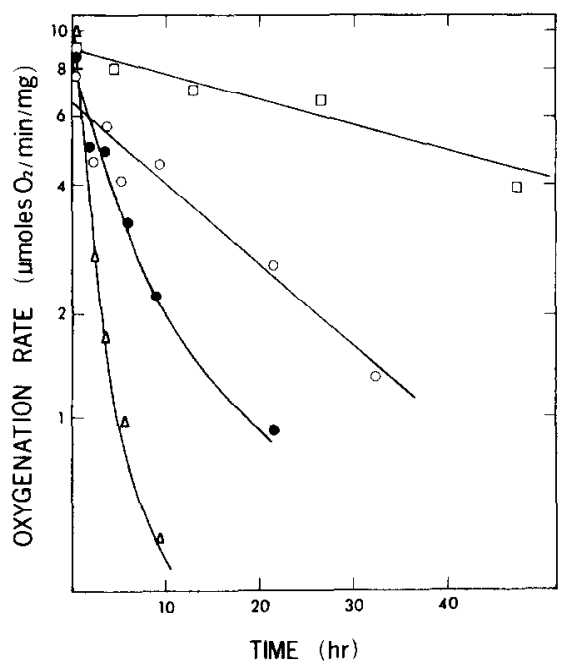

FIG. 1. The effect of varied levels of heme on cyclooxygenase stability. Cyclooxygenase $(0.86 \mu \mathrm{M}$ subunit, 520 units $/ \mathrm{ml}$ ) was incubated at $21-23^{\circ} \mathrm{C}$ in the presence of $0.03 \mu \mathrm{M}(0), 0.07 \mathrm{M}(\Delta), 0.9 \mu \mathrm{M}(0)$, or $10.6 \mu \mathrm{M}(\square)$ total heme. At the indicated times, $100-\mu$ l aliquots were withdrawn and assayed for 20:4 oxygenase activity as described under Materials and Methods.

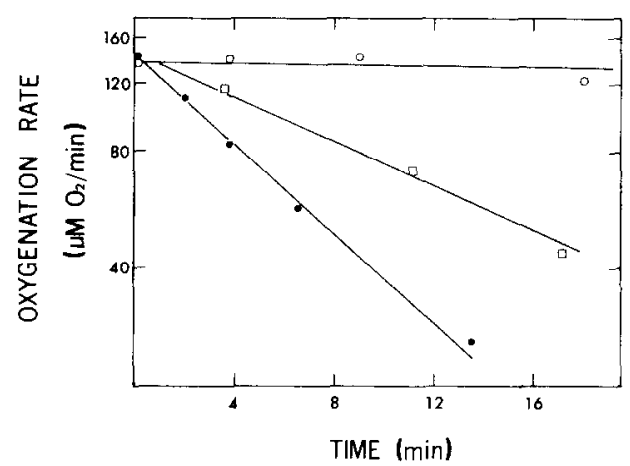

FIG. 2. Glutathione peroxidase prevention of cyclooxygenase inactivation. Cyclooxygenase $(0.092 \mu \mathrm{M}$, $21,000 \mathrm{units} / \mathrm{mg})$ in the presence of heme $(0.033 \mu \mathrm{M})$ was incubated at $30^{\circ} \mathrm{C}$ with 1270 units $/ \mathrm{ml}$ of GSP and $0.5 \mathrm{~mm}$ GSH (O); GSP, GSH, and $1.0 \mathrm{~mm} N$-ethyl maleimide ( $\square$ ); and with no additions (๑). At the indicated times, 20:4 was added to initiate oxygenation.

0.03 (half-life, $4.4 \mathrm{~h}$ ) to $0.07 \mu \mathrm{M}$ (half-life, $1.3 \mathrm{~h}$ ), a stoichiometric hematin concentration $(0.9 \mu \mathrm{M})$ caused less inactivation giving a 17-h half-life which was lengthened to $40 \mathrm{~h}$ with excess heme $(10.6 \mu \mathrm{M})$. The preparation with an apparent heme content of $0.03 \mu \mathrm{M}$ (by spectrophotometric analysis) was completely apoenzyme on a functional basis (see Materials and Methods). Unfortunately, the removal of all traces of heme to obtain a $0 \mu \mathrm{M}$ hematin preparation was prohibitively difficult (see Discussion).

\section{Protection against Spontaneous Inactivation}

Enzyme stability at $30^{\circ} \mathrm{C}$ was also examined in the presence and absence of the peroxide scavenger, glutathione peroxidase (GSP) and its substrate, glutathione. Cyclooxygenase incubated for $18 \mathrm{~min}$ with GSP retained $100 \%$ activity but only $5 \%$ activity remained after $13.5 \mathrm{~min}$ in the absence of GSP (Fig. 2). Removal of glutathione (GSH), the essential cosubstrate for GSP activity, by treatment with $N$-ethyl maleimide significantly decreased the ability of GSP to protect the cyclooxygenase against destruction. Since our GSP preparations contained GSH for stability, it was not feasible to add GSP alone: Addition of $N$-ethyl maleimide alone had no effect on cyclooxygenase stability, and GSH alone afforded no protec- 


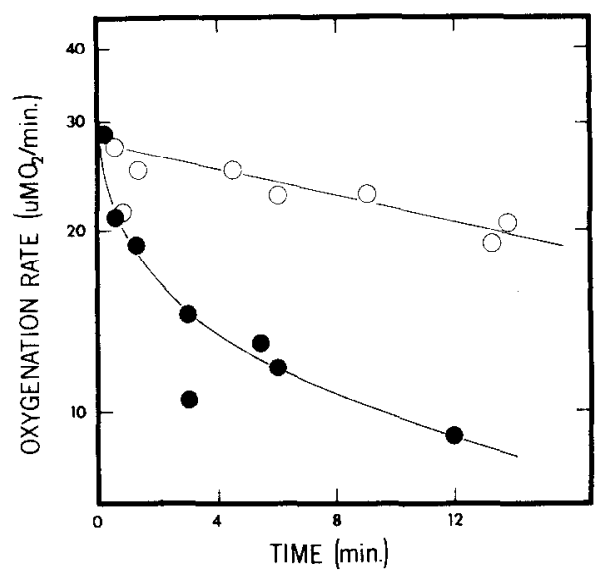

FIG. 3. Catalase protection of cyclooxygenase at $30^{\circ} \mathrm{C}$. Cyclooxygenase $(0.04 \mu \mathrm{M} ; 10,000$ units $/ \mathrm{mg})$ in the presence of hematin $(5.8 \mu \mathrm{M})$ was incubated at $30^{\circ} \mathrm{C}$ without $(\bigcirc)$ or with catalase $(\bigcirc)$ at 2000 units $/ \mathrm{ml}$. At the indicated times, $20: 4(50 \mu \mathrm{M})$ plus phenol $(0.67$ $\mathrm{mm}$ ) were added to initiate oxygenation.

tion, but slightly facilitated the destructive process (data not shown).

The effect of catalase was examined to determine if $\mathrm{H}_{2} \mathrm{O}_{2}$ was involved in spontaneous destruction of cyclooxygenase (Fig. 3). Catalase protected cyclooxygenase during incubation with hematin. Only $26 \%$ of the activity was lost in $12 \mathrm{~min}$ in the presence of calalase $(2000 \mu / \mathrm{ml})$ compared to $69 \%$ inactivation in the absence of catalase. Paradoxically, low levels of catalase $(\sim 100 \mu / \mathrm{ml})$ destabilized rather than stabilized cyclooxygenase during incubations in the presence of trace amounts of hematin (Table III). Only $18 \%$ of the activity remained after $1.7 \mathrm{~min}$ in the presence of $100 \mu / \mathrm{ml}$ catalase compared to $77 \%$ remaining after $4.7 \mathrm{~min}$ in the absence of catalase.

As an alternative to adding a large excess of hematin (as in Fig. 1) moderate amounts of hematin and phenol together provided very effective stabilization (Fig. 4). Hematin alone, at a stoichiometry of two hemes per subunit, provided a half-life (ca. $18 \mathrm{~h}$ ) comparable to that seen with stoichiometric levels of heme in Fig. 1. Phenol alone was even less effective as a protective agent, allowing loss of half the enzyme in 8 to $13 \mathrm{~h}$. However, the combined action of phenol and heme provided almost complete recovery of cyclooxygenase activity after $24 \mathrm{~h}$ at room temperature. These effects were used to aid in cyclooxygenase purification, which we now perform in the presence of $1.0 \mathrm{~mm}$ phenol and $25 \mu \mathrm{M}$ hematin. Using these conditions, we can consistently achieve high recoveries of activity (43-90\%, Table IV). The isoelectric focusing step, for example, routinely yielded $95-100 \%$ recovery of activity, whereas in the absence of hematin and phenol, only $20-50 \%$ had been recovered (data not shown).

\section{Protection of Cyclooxygenase Acetone Powder Preparations}

Prompted by new insights regarding the heme-protein nature of cyclooxygenase, and the destabilizing and protective effects of heme and phenol, we reexamined the phenomenon of phenol-mediated time-dependent activation of acetone powder preparations (12). A characteristic activation curve (Fig. 5 , curve F) shows 10 - to 20 -fold activation by phenol in $165 \mathrm{~min}$ at $21-23^{\circ} \mathrm{C}$. By contrast, in the absence of added phenol (curve A), no increase in activity was observed. The progressive activation by phenol was largely prevented in the presence of globin (curve C). After 47 min (arrow), the addition of excess hematin (four times the concentration of globin) neither restored cyclooxygenase activity nor allowed phenol activation to occur. Since such a level of heme would be enough to reverse globin inhibition (not

\section{TABLE III}

The Failure of Catalase to Prevent CyClOOXYGENASE INACTIVATION ${ }^{n}$

\begin{tabular}{|c|c|c|c|}
\hline \multicolumn{2}{|c|}{$(+)$ Catalase } & \multicolumn{2}{|c|}{ (-) Catalase } \\
\hline $\begin{array}{l}\text { Time } \\
\text { (min) }\end{array}$ & $\begin{array}{c}\text { Oxygenation } \\
\text { rate (nmol/ } \\
\mathrm{min} / \mathrm{mg} \text { enzyme) }\end{array}$ & $\begin{array}{l}\text { Time } \\
(\min )\end{array}$ & $\begin{array}{c}\text { Oxygenation } \\
\text { rate (nmol/ } \\
\mathrm{min} / \mathrm{mg} \text { enzyme) }\end{array}$ \\
\hline 0 & 8,500 & 0 & 11,200 \\
\hline 0.2 & 4,800 & 0.6 & 10,600 \\
\hline 0.9 & 4,700 & 2.0 & 9,700 \\
\hline 1.7 & 1,500 & 4.7 & 8,700 \\
\hline
\end{tabular}

${ }^{a}$ Cyclooxygenase $(0.05 \mu \mathrm{M}, 30-50 \%$ holoenzyme) was preincubated in standard reaction chambers at $30^{\circ} \mathrm{C}$ in the absence and presence of catalase $(100$ units $/ \mathrm{ml}$ ) for the indicated time intervals. Then 20:4 was added to initiate oxygenation. At zero time substrate was added prior to enzyme. 
shown), most of the cyclooxygenase activity must have been lost during the initial $47 \mathrm{~min}$ in the absence of phenol. Furthermore, in the absence of phenol increased amounts of hematin (Fig. 5) caused both increased initial rates of activation and higher final extents of activation.

The time-dependent activation of the labile cyclooxygenase in the acetone powder preparation was favored by conditions (phenol and high levels of heme) likely to protect the enzyme from spontaneous destruction. This observation suggested that protection was a key feature of the time-dependent activation process. Thus DDC, also known to be a protective agent (Rome and Lands, 1975) was tested by itself (Fig. 6, curve B) or in the presence of heme (curve D), for time-dependent stimulation of the cyclooxygenase. In each case, activation was two- to threefold greater than for corresponding samples without DDC (curves A and $\mathrm{C}$ ). The correct stoichiometry of approximately two oxygen molecules per $20: 4$ consumed has been observed in studies using

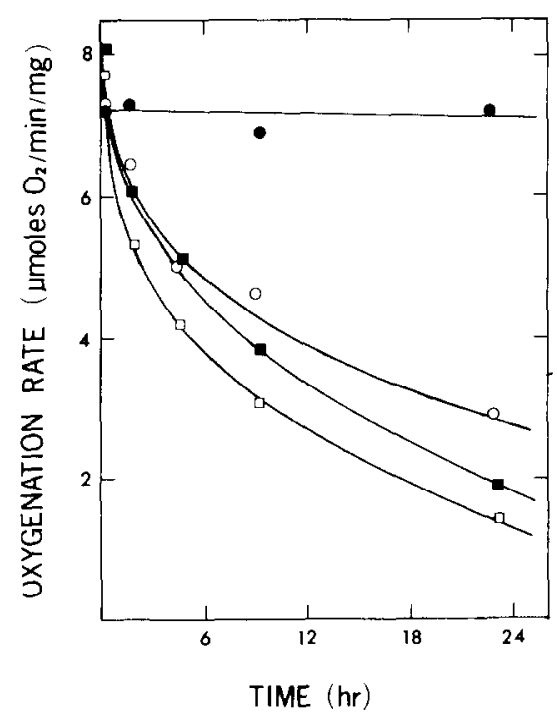

FIG. 4. The synergistic stabilizing effect of phenol and heme. Partially purified cyclooxygenase (through DEAE-cellulose) was dialyzed as described under Materials and Methods to remove DDC and the enzyme (8000 units $/ \mathrm{ml}$, ca. $12 \mu \mathrm{M}$ subunit, $<5 \%$ holoenzyme) was stored at $21-23^{\circ} \mathrm{C}$ with no additions ( $\left.\square\right), 0.67 \mathrm{mM}$ phenol $(\square), 20 \mu \mathrm{M}$ hematin $(O)$, or phenol plus hematin (๑). Aliquots were assayed for 20:4 oxygenase activity at the indicated times.
TABLE IV

PuRIFICATION OF OVINE CYCLOOXYGenase IN HIGH YIELD ${ }^{a}$

Total units $\left(\times 10^{6}\right)$

\begin{tabular}{lccr}
\hline & \multicolumn{3}{c}{ Total units $\left(\times 10^{6}\right)$} \\
\cline { 2 - 4 } \multicolumn{1}{c}{ Procedure } & Prep A & Prep B & Prep C \\
\hline Ammonium sulfate & & & \\
$\quad$ fractionation & 4.0 & 7.6 & 11.1 \\
DEAE I & 3.9 & 5.9 & 7.5 \\
DEAE II & 3.9 & 3.8 & 7.3 \\
Isoelectric focusing & 4.2 & 3.6 & 7.8 \\
DEAE III & 3.6 & 3.3 & 5.4 \\
\hline
\end{tabular}

"Phenol (1 mM) and hematin (25 $\mu \mathrm{M})$ were included in each purification step. Frozen sheep vesicular glands were homogenized as previously described (1) and centrifuged at $13,000 \mathrm{~g}$ for $10 \mathrm{~min}$. Then the supernatant was centrifuged at $100,000 \mathrm{~g}$ to obtain the microsomal pellet. Microsomes were homogenized in buffer containing $1.0 \mathrm{mM}$ phenol and $0.1 \mathrm{~m}$ Tris-chloride (pH 8.5), made $2 \%$ with Tween 40 (550 ml total volume) and allowed to solubilize for $45 \mathrm{~min}$ at $0^{\circ} \mathrm{C}$. Ammonium sulfate fractionation, dialysis, and DEAE-cellulose chromatography in the presence of DDC were carried out as described (1). Excess DDC was removed by passage over DEAE-cellulose equilibrated in $0.02 \mathrm{M}$ potassium phosphate ( $\mathrm{pH} 7.0$ ), $1.0 \mathrm{~mm}$ phenol, $1 \%$ Tween 40 and $20 \%$ glycerol. Isoelectric focusing was carried out as described previously (1), and excess heme was then removed by chromatography on DEAE-cellulose equilibrated in $0.02 \mathrm{M}$ potassium phosphate, $1.0 \mathrm{~mm}$ phenol, $20 \%$ glycerol, and $0.2 \%$ Tween 40 .

acetone powder preparations in the presence and absence of phenol activation (12) as well as with purified cyclooxygenase preparations in the presence or absence of phenol or DDC (17). Thus the determination of oxygen consumption with arachidonic acid (Figs. 5 and 6) is reliably indicative of prostaglandin formation.

In contrast to results with the acetone powder, freshly ground homogenates of whole glands showed only 1.3-fold or less activation by phenol, and highly purified cyclooxygenase preparations showed no time-dependent phenol activation phenomenon. Rather, the pure apoenzyme was instantaneously "activated" by added hematin (see above).

\section{DISCUSSION}

The finding that heme destabilizes ovine cyclooxygenase is in agreement with the 


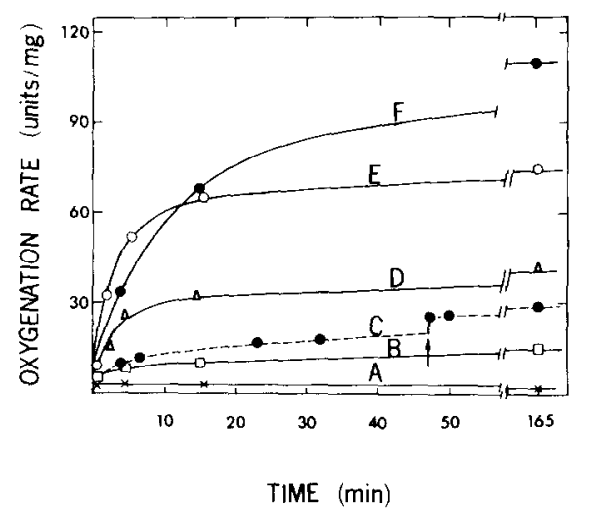

FIG. 5. Time-dependent activation of cyclooxygenase by phenol and heme. Freshly homogenized acetone powder $(100 \mathrm{mg} / \mathrm{ml})$ in $1.0 \mathrm{ml}$ of $0.1 \mathrm{M}$ Tris $-\mathrm{HCl}(\mathrm{pH}$ 8.5) was allowed to stand at $21-23^{\circ} \mathrm{C}$ with: $\mathrm{A}$, no additions (X); B, $8.4 \mu \mathrm{M}$ hematin $(\square)$; D, $42 \mu \mathrm{M}$ hematin $(\triangle)$; E, $103 \mu \mathrm{M}$ hematin $(\mathrm{O}) ; \mathrm{F}, 0.67 \mathrm{mM}$ phenol (-); C, $2 \mathrm{mg}$ globin plus $0.67 \mathrm{~mm}$ phenol (---). After $47 \mathrm{~min}, 147 \mu \mathrm{M}$ hematin was added (arrow) to the globin preincubation mixture (C). At the indicated times, enzyme assays were initiated by transfer of $80-\mu \mathrm{l}$ aliquots to $3 \mathrm{ml}$ reaction chambers containing 20:4 $(50 \mu \mathrm{M})$ and phenol $(0.67 \mathrm{mM})$. For assay of the globin mixture (C), $6 \mu \mathrm{M}$ hematin was included in the assay chambers.

results found for bovine cyclooxygenase (5). However, in contrast to the results with the bovine enzyme, stoichiometric or greater levels of heme were significantly less destructive than trace levels of heme, for ovine cyclooxygenase. Furthermore, globin protected against heme-induced destruction (Tables I, II). This result suggests that the heme bound to cyclooxygenase (which is removed by the globin) rather than heme residing on another protein is active in causing destruction.

New insight into the mechanism of hemeinduced destruction has been gained from the results showing protection by glutathione peroxidase and catalase. These results are consistent with a mechanism involving destruction by trace amounts of peroxide. In this regard, cyclooxygenase (in the absence of a protective agent such as phenol) is highly vulnerable to destruction by $\mathrm{H}_{2} \mathrm{O}_{2}$ (9) and lipid hydroperoxides. For example, the half-life of a cyclooxygenase preparation in the absence of added peroxide $\left(\tau_{1 / 2}=68 \mathrm{~s}\right)$ was decreased sevenfold $\left(\tau_{1 / 2}=9.9 \mathrm{~s}\right)$ in the presence of $7.3 \mu \mathrm{M}$ lipid hydroperoxide (Hemler and Lands, in press).

Low concentrations of catalase, which is an inefficient scavenger of $\mathrm{H}_{2} \mathrm{O}_{2}$ (19) and has $K_{m}^{\text {app }}$ for $\mathrm{H}_{2} \mathrm{O}_{2}$ of $1.1 \mathrm{M}(20)$, did not protect cyclooxygenase against inactivation. This amount of catalase caused increased destruction rather than protection (Table III) perhaps because of free heme contamination present in the commercial preparation, or because of an exchange of heme between the two enzymes. Alternatively, traces of lipid peroxide may be formed but not removed by catalase. These considerations may also explain why added catalase did not protect the bovine cyclooxygenase from inactivation (5).

Recognition that peroxides may mediate spontaneous destruction of cyclooxygenase now allows interpretation of the protection of cyclooxygenase by cosubstrates of the prostaglandin hydroperoxidase (see introduction). Cosubstrates, such as phenols, indoles and other compounds stimulate the removal of peroxides, including $\mathrm{H}_{2} \mathrm{O}_{2}(5,9$, 10). Thus prostaglandin hydroperoxidase appears to protect the cyclooxygenase by a mechanism analogous to that with glutathione peroxidase or catalase. The discovery that protection by phenol was observed only when adequate heme was also available (Fig. 4) is consistent with the established heme requirement for the prostaglandin hydroperoxidase activity $(3,5,9,10)$.

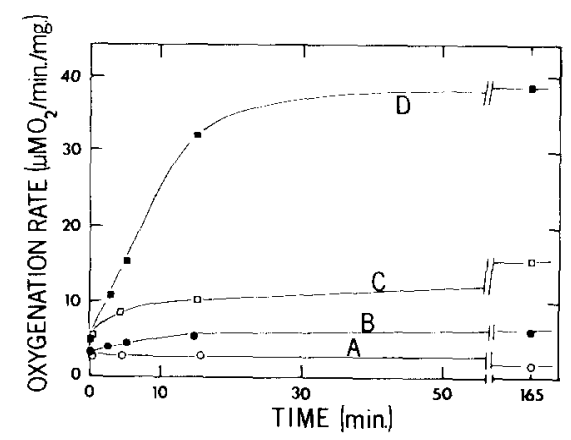

FIG. 6. Time-dependent activation of cyclooxygenase by DDC and heme. Using preincubation and assay conditions as in Fig. 4, acetone powder was preincubated with: A, no additions (O); B, $8.4 \mu \mathrm{M}$ hematin ( [] ); $\mathrm{C}, 10 \mathrm{mM}$ DDC (O); D, $8.4 \mu \mathrm{M}$ hematin plus $10 \mathrm{mM}$ DDC ( $\square$ ). The data for A and B are the same as in Fig. 4. 
High levels of heme may protect the vulnerable site(s) on the enzyme from destruction, or may confer increased thermal or physical stability on cyclooxygenase such as observed for hemoglobin (21). It is also possible that high levels of heme have some peroxidase activity even in the absence of added hydroperoxidase cosubstrates (10). Hematin can also have a low level of catalatic activity (22). These possibilities may help explain the increased protection seen with stoichiometric or greater levels of heme, compared with trace amounts of heme (discussed above). Diethyldithiocarbamate had been shown to protect cyclooxygenase during storage (8) and has been previously included during purification. Now its mode of action may be explained by its ability to reduce peroxides [half-life of $\mathrm{H}_{2} \mathrm{O}_{2}$ is 1 min at $\mathrm{pH} 7.5$ with $5 \mathrm{~mm}$ DDC (23)]. The process of heme-induced destruction of cyclooxygenase during storage shows striking similarity to destruction by acetylenic substrate analogs (24). That destructive process required heme and is inhibited by phenol (Hemler and Lands, unpublished observations) and by catalase (24).

The discovery of the roles of heme and phenol in the destabilization and stabilization of cyclooxygenase has had considerable practical benefit for handling the purification of the enzyme. As shown in this study, it is unfeasible to attempt purification of holoenzyme without a protective agent present. During past purifications from sheep vesicular glands $(1,9)$, selective destruction of holoenzyme undoubtedly contributed to the low yields and to the high proportion of apoenzyme which was obtained. One tactic to avoid this problem is to remove the heme. However, incubation with globin was only partially successful, and no other techniques were found to remove heme quickly and efficiently. Since the apoenzyme alone may still be a little unstable (see below), we felt that a better approach in maintaining activity was to add extra heme along with the protective agent, phenol.

The preparation of acetone-powders had been a common, convenient method of handling crude cyclooxygenase since 1971 (16), and we have routinely pretreated these preparations with phenol to increase their activity $(11,12)$. The role of heme gives new insight into the mechanism of this slow timedependent phenol activation. The results suggest that the time-dependent activation involves a slow conversion of apoenzyme to holoenzyme which is inhibited when added globin binds the endogenous heme and is facilitated when additional heme is added directly, even in the absence of phenol. The time-dependent activation phenomenon was hardly noticeable in freshly ground homogenates of sheep vesicular gland (undepleted of heme), but apparently the acidification and trealment with organic solvent during the preparation of acetone powder causes a partial removal of heme (25) bound to cyclooxygenase. Purified preparations of cyclooxygenase do not show a slow time-dependent activation. Presumably equilibration with heme is very rapid in the absence of large amounts of contaminating proteins. Another dioxygenase, tryptophan oxygenase, has also ben observed to undergo a slow activation upon incubation of crude homogenates with heme protein, and that process could also be inhibited by globin (26).

Further insight comes from the fact that a time-dependent activation is facilitated also by agents which protect cyclooxygeinase. These results are consistent with the expectation (see above) that low levels of endogenous heme in acetone powders would make this preparation vulnerable to destruction and the slow activation would not be seen unless protection was provided. Also, the higher extent of activation which occurs with higher amounts of heme, probably reflects the greater stability of cyclooxygenasc preparations containing high levels of heme.

Another aspect of the activation of acetone powders is that phenol, DCC, and several other agents can directly stimulate cyclooxygenase when present during catalysis $(4,12,17,27)$. However, that stimulation is immediate (within seconds) and occurs with almost all other preparations of cyclooxygenase in addition to acetone powders. Because it appears distinct from the slow time-dependent activation seen during preincubation of acetone powders with phenol, the mechanism of that rapid stimulation is addressed in a separate discussion of the 
cyclooxygenase reaction mechanism (Hemler and Lands, in press).

The previously described conversion of an $\mathrm{Eb}$ form of cyclooxygenase to an $\mathrm{Ea}$ form (12) during phenol activation now might be regarded as a process of slow holoenzyme formation from apoenzyme in the crude preparations. The increased sensitivity of the phenol-activated Ea enzyme to GSP inhibition has been explained as a synergistic inhibitory effect of enzyme-phenol interactions in the presence of GSP (28).

In summary, the cyclooxygenase from sheep vesicular glands is inherently unstable in the presence of low amounts of heme. The destructive process appears to be mediated by spontaneously formed trace amounts of peroxide. This new understanding of enzyme instability and modes of protection means that large spontaneous losses of enzyme activity which previously hampered purification and storage procedures can now be avoided. In addition, the time-dependent increase in activity with phenol which slowly produces the $\mathrm{Ea}$ form of activity is now consistent with a mechanism whereby the protected holoenzyme in acetone powder slowly accumulates as apo-cyclonxygenase equilibrates with the endogenous heme that is present.

\section{ACKNOWLEDGMENTS}

This work was supported in part by a grant from the National Science Foundation (BMS-75-73157) and an Upjohn Graduate Research Fellowship (M.E.H.). We thank A. Hanel for excellent assistance in preparing purified cyclooxygenase.

\section{REFERENCES}

1. Hemler, M., Lands, W. E. M., AND SMith, W. L. (1976) J. Biol. Chem. 251, 5575-5579.

2. Hemler, M. E., ANd Lands, W. E. M. (1977) Lipids 12, 591-595.

3. Van der OUderaA, F. J., BuytenheK, M., SlikkerVeER, L. J., AND VAN DorP, D. A. (1979) Biochim. Biophys. Acta 572, 29-42.

4. Miyamoto, T., Ogino, N., Yamamoto, S., and
Hayaishi, O. (1976) J. Biol. Chem. 251, 2629-2636.

5. Ogino, N., Ohki, S., Yamamoto, S., and HayaISHI, O. (1978) J. Biol. Chem. 253, 5061-5068.

6. Yoshimoto, A., Ito, H., And Tomita, K. (1970) J. Biochem. 68, 487-499.

7. Samuelsson, B. (1969) Progr. Biochem. Pharmacol. 5, 109-128.

8. Rome, L. H., ANd Lands, W. E. M. (1975) Prostaglandins 10, 813-824.

9. VAN der OuderaA, F. J., Buytenhek, M., Nugteren, D. H., AND Van DoRP, D. A. (1977) Biochim. Biophys. Acta 487, 315-331.

10. OHKi, S., OGino, N., Yamamoto, S., and HayaISHI, O. (1979) J. Biol. Chem. 254, 829-836.

11. Smith, W. L., AND Lands, W. E. M. (1971) $J$. Biol. Chem. 247, 1038-1047.

12. Smith, W. L., AND Lands, W. E. M. (1972) Biochemistry 11, 3276-3285.

13. FALK, J. E. (1964) in Porphyrins and Metalloporphyrins, Elsevier, New York.

14. Teale, F. W. J. (1959) Biochim. Biophys. Acta $35,543$.

15. CoOK, H. W., AND LANDS, W. E. M. (1975) Canad. J. Biochem. 53, 1220-1231.

16. Wallach, D. P., and Daniels, E. G. (1971) Biochim. Biophys. Acta 231, 445-457.

17. Hemler, M. E., CRaWford, C. G., and Lands, W. E. M. (1978) Biochemistry 12, 1772-1779.

18. Beers, R. F., JR., ANd Sizer, I. W. (1952) $J$. Biol. Chem. 195, 133-140.

19. MisRa, H. (1974) J. Biol. Chem. 249, 2151-2155.

20. OGura, Y. (1955) Arch. Biochem. Biophys. 57, 288-300.

21. Rossi-Fanelli, A., Antonini, E., and Caputo, A. (1959) Biochim. Biophys. Acta 35, 93-101.

22. Dunford, H. R., and STILlman, J. S. (1976) Coordination Chem. Rev. 19, 187-251.

23. IShimURA, Y., AND HAYAISHI, O. (1973) J. Biol. Chem. 248, 8610-8612.

24. VANDERHOEK, J. U., AND LANDS, W. E. M. (1978) Prostaglandins Med. 1, 251-263.

25. ANTONINI, E., AND BRUNori, M. (1971) Hemoglobin and Myoglobin in their Reactions with Ligands, North-Holland, Amsterdam.

26. Knox, W. E., and Piras, M. M. (1966) J. Biol. Chem. 241, 764 .

27. Takeguchi, C., Kohno, E., ANd Lih, C. J. (1971) Biochemistry 10, 2372-2376.

28. Hemler, M. E., AND LandS, W. E. M. (1979) in Oxygen: Biochemical and Clinical Aspects (Caughey, W. S., ed.), Academic Press, New York. 